\title{
Viral aetiology of bronchiolitis in hospitalised children in Qatar
}

\author{
Ibrahim Janahi ${ }^{1 *}$, Anas Abdulkayoum² ${ }^{2}$ Fawziya Almeshwesh', Mohamed Alkuwari ${ }^{1}$, Ahmed Al hammadi \\ and Marwah Alameri ${ }^{1}$
}

\begin{abstract}
Background: Bronchiolitis is considered one of the earliest and most common causes of hospitalisation in young children. Development of molecular technologies allowed a better understanding of bronchiolitis aetiology. Results from cohort studies evaluating the association between single, multiple viral infections and clinical outcomes are conflicting. Data on viral bronchiolitis in children were found to be limited in Qatar. This study aimed to determine frequency and seasonal trends of viral pathogens causing acute bronchiolitis, and to explore association between viral pathogens, disease severity and length of stay (LOS).

Methods: This is a retrospective descriptive study, including children admitted in 2010 and 2011 with acute bronchiolitis. Presenting history, physical examination and respiratory viral co-infections as detected by molecular assays were analysed.

Results: At least one virus was detected in 315/369 (85.4\%) of included children with single and multiple viruses in 67 and 33\% of cases respectively. Respiratory syncytial virus (RSV) was the most detected virus, accounting for 51. $2 \%$ followed by rhinovirus (RV) in $25.5 \%$ of cases. Fall and summer admissions were associated with longer LOS. On multivariate logistic regression analysis, retraction (OR 3.96; 95\% Cl 1.64,9.59) and age group 1-3 months (OR 3.09; $95 \% \mathrm{Cl} 1.06,9.05)$ were associated with longer LOS. Crepitation (OR 9.15; 95\% Cl 1.58,53.13), retraction (OR 4.10; 95\% $\mathrm{Cl} 1.05,16.12)$ and respiratory rate $(\mathrm{OR} 1.46 ; 95 \% \mathrm{Cl} 1.28,1.66)$ were associated with moderate to severe bronchiolitis. Identifying the viral agent did not influence disease severity or LOS.

Conclusion: Clinical presentation is of more relevance to LOS and disease severity than the detected viruses. Future studies should investigate the interplay between climate characteristics, population's factors and the most detectable circulating viruses.
\end{abstract}

Keywords: Length of stay, Bronchiolitis severity, Multivariate predictors

\section{Background}

Bronchiolitis is considered one of the earliest and most common causes of hospitalisation among young children during their first 2 years of life [1]. Although the causative agents include bacteria, fungi and viruses, this acute infection is mainly attributed to respiratory syncytial virus, accounting for $50-90 \%$ of the cases $[2,3]$. With the current utilisation of reverse transcriptase real-time polymerase chain reaction (PCR), the detection of specific viral nucleic acids

\footnotetext{
* Correspondence: ijanahi@hamad.qa

${ }^{1}$ Paediatric Pulmonology Unit, Hamad Medical Corporation, P. O. Box 3050,

Doha, Qatar

Full list of author information is available at the end of the article
}

facilitated a better understanding of the viral aetiology of the infection. The 2014 American Academy of Paediatrics bronchiolitis guideline recommends against the routine use of radiographic or laboratory studies on the basis that knowing the infecting pathogen would rarely alter the clinical management [4]. However, a growing body of literature has identified an association between specific infecting pathogens with short and long-term outcomes [5]. Association between viral co-infection and disease severity have been assessed in several studies but with conflicting findings [5-7]. Although bronchiolitis is a self-limiting condition, hospitalisation rate has increased during the last two decades [3]. Assessment of bronchiolitis 
severity, through a combination of clinical symptoms and physical signs, remains a standard measure in daily practice though its impact on clinical outcomes, such as length of hospital stay, has yet to be confirmed. Data has been reported on seasonal variation of viral activity with conflicting evidence on its significance on disease severity and clinical outcomes $[8,9]$. In Qatar, viral aetiology of bronchiolitis in children has been limited. Therefore the aims of this retrospective, descriptive study were: to determine the frequency and seasonal trends of viral pathogens causing acute bronchiolitis, and to explore the association between specific viral pathogens, disease severity and length of stay (LOS).

\section{Methods}

\section{Study design}

This retrospective descriptive study took place at the paediatric wards of Hamad General Hospital (HGH), a 603- bed, tertiary-care facility in Doha, for two consecutive years, 2010 and 2011. The institutional review board at Hamad Medical Corporation approved the study, IRB number 12054.

\section{Study population}

The study population included children aged between 2 weeks- 2 years admitted to the paediatric ward at $\mathrm{HGH}$ with a diagnosis of acute bronchiolitis defined according to International Classification of Disease (ICD) code 466.1 in the $9^{\text {th }}$ revision of the ICD. Based on recorded clinical diagnosis, an episode of acute bronchiolitis was determined by a constellation of clinical signs and symptoms including fever, rhinitis, tachypnoea, cough, wheezing, crackles, use of accessory muscles and possible chest $\mathrm{X}$ ray findings of hyperinflation of the lungs, peri-bronchial thickening, collapsed segment or a lobe of the lung and increase interstitial markings. Due to the potential for an atypical natural history of bronchiolitis, children with the following diagnoses were excluded: born prematurely, defined as $<37$ weeks of gestation, those with low birth weight, defined as birth weight $<2.5 \mathrm{~kg}$, with underlying chronic lung disease or neurological disease or congenital heart disease, and those immunocompromised or with hospital-acquired bronchiolitis.

\section{Data collection}

Medical charts of the children admitted to the paediatric ward during the study period were retrieved from the medical records department at $\mathrm{HGH}$, a tertiary teaching hospital located in Doha, Qatar. A trained research staff screened patients' discharge summaries for diagnosis of bronchiolitis. A data collection form (DCF) was developed to capture the necessary information. For every child who met the inclusion criteria the following data were collected: age, gender, family history of asthma and/or atopy, clinical presentation and vital signs upon admission and length of hospital stay. Bronchiolitis severity was based on a score ranging between 1 and 5 that assessed wheezing, retraction, respiratory rate and oxygen saturation (see Additional file 1: Table S1). Patients with score of 1 or 2 were considered to have mild bronchiolitis and to have moderate to severe bronchiolitis if score was between 3 and 4, with 5 indicating respiratory failure. Wheezing on physical exam was categorised as none, mild, moderate or severe. Retraction was categorised as none, intercostal, intercostal and subcostal or intercostal and subcostal with seesaw chest motion. Viral identification laboratory results, medical therapy and need of mechanical ventilation during hospital stay were recorded. Hospital admissions due to bronchiolitis were presented on an episode base.

\section{Nasopharyngeal sample collection and analysis}

Nasopharyngeal samples were collected by inserting Dacron $^{\text {Th }}$ polyester tipped or FLOQSwab ${ }^{\text {TM }}$ in both nostrils till the nasopharynx and rotating at $360^{\circ}$. The swabs were placed into $3 \mathrm{ml}$ of transport medium (Copan, UTM-RT ${ }^{\mathrm{Tx}}$, CA, USA). Following collection, samples were kept on wet ice and transported to central processing lab of $\mathrm{HGH}$ during the working hours. Specimens that were not delivered immediately to the lab were stored in a refrigerator $\left(4-8{ }^{\circ} \mathrm{C}\right)$ for no more than $24 \mathrm{~h}$. Beyond that, samples were stored at $-70{ }^{\circ} \mathrm{C}$ and transported on dry ice. EZ1 virus mini kit $\mathrm{v} 2.0$, was used for nucleic acid extraction (Qiagen ${ }^{\circ}$ Hilden, Germany). Multiplex, real-time, polymerase chain reaction (RTPCR) using FTDResp21 kit (Fast Track Diagnostics, Silema, Malta) was used for the detection of respiratory pathogens on Applied Biosystem ${ }^{\text {TM }} 7500$ instrument (ThermoFisher Scientific Inc, MA, USA). The kit detects the following respiratory pathogens: influenza A and B; coronaviruses NL63, 229E, OC43 and HKU1; parainfluenza viruses $1,2,3$ and 4; human metapneumovirus A/B (hMPV); rhinovirus (RV); respiratory syncytial virus A/B (RSV); adenovirus (AdV); enterovirus (EV); parechovirus $(\mathrm{PeV})$; bocavirus $(\mathrm{BoV})$ and Mycoplasma pneumoniae (Mpneu).

\section{Statistical analysis}

The focus of the data analysis in our study was to determine frequency of each virus that is causing acute bronchiolitis in young children in our community and link it to the clinical presentation, length of hospital stay, severity of symptoms and need for intensive care support including invasive and non invasive ventilation. Categorical and continuous values were expressed as 
Table 1 Demographic characteristics, clinical presentation and symptoms, viral etiology and management of children with acute bronchiolitis

\begin{tabular}{|c|c|}
\hline Characteristics & Frequency $(\%$ \\
\hline \multicolumn{2}{|l|}{ Gender $(n=369)$} \\
\hline Male & $247(66.9 \%)$ \\
\hline Female & $122(33.1 \%)$ \\
\hline \multicolumn{2}{|l|}{ Age (months) $(n=347)$} \\
\hline$<1$ months & $144(41.5 \%)$ \\
\hline 1 to 3 months & $117(33.7 \%)$ \\
\hline$>3$ months & $86(24.8 \%)$ \\
\hline \multicolumn{2}{|l|}{ Clinical and presenting symptoms $(n=369)$} \\
\hline Cough & $348(94.3 \%)$ \\
\hline Wheezing & $231(62.6 \%)$ \\
\hline Rales & $15(4.1 \%)$ \\
\hline Crepitation & $270(73.2 \%)$ \\
\hline Retraction & $251(68.0 \%)$ \\
\hline Fever & $261(70.7 \%)$ \\
\hline Apnea & $24(6.5 \%)$ \\
\hline Pertussis like symptoms & $29(7.9 \%)$ \\
\hline Family history of atopy or asthma & $145(39.3 \%)$ \\
\hline Max. Temperature $\left({ }^{\circ} \mathrm{C}\right)(n=353)$ & $38.49 \pm 0.80$ \\
\hline Max. Respiratory rate $(\mathrm{br} / \mathrm{m})(n=351)$ & $62.51 \pm 13.65$ \\
\hline Max. Pulse $($ beat $/ m)(n=351)$ & $167.88 \pm 19.1$ \\
\hline $\mathrm{O}_{2}$ Saturation $(\%)(n=341)$ & $96.40 \pm 2.46$ \\
\hline \multicolumn{2}{|l|}{ Initial Clinical Severity Score $(n=349)$} \\
\hline 1 & $19(5.4 \%)$ \\
\hline 2 & $142(40.7 \%)$ \\
\hline 3 & $159(45.6 \%)$ \\
\hline 4 & $26(7.4 \%)$ \\
\hline 5 & $3(0.9 \%)$ \\
\hline \multicolumn{2}{|l|}{ Nationality $(n=369)$} \\
\hline Qatari & $234(63.4 \%)$ \\
\hline Non-Qatari & $135(36.6 \%)$ \\
\hline \multicolumn{2}{|l|}{ Seasons $(n=355)$} \\
\hline Winter & $154(43.4 \%)$ \\
\hline Spring & $43(12.1 \%)$ \\
\hline Summer & $20(5.6 \%)$ \\
\hline Fall & $138(38.9 \%)$ \\
\hline \multicolumn{2}{|l|}{ Viral Etiology $(n=369)$} \\
\hline RSV & $189(51.2 \%)$ \\
\hline Influenza A & $3(0.8 \%)$ \\
\hline Influenza B & $1(0.3 \%)$ \\
\hline Paralnfluenza 1 & $4(1.1 \%)$ \\
\hline Paralnfluenza 2 & $4(1.1 \%)$ \\
\hline Paralnfluenza 3 & 19 (5.1\%) \\
\hline
\end{tabular}

Table 1 Demographic characteristics, clinical presentation and symptoms, viral etiology and management of children with acute bronchiolitis (Continued)

\begin{tabular}{ll}
\hline Paralnfluenza 4 & $3(0.8 \%)$ \\
Corona_NL63 & $3(0.8 \%)$ \\
Corona_COC43 & $16(4.3 \%)$ \\
Corona_229E & $2(0.5 \%)$ \\
Corona_HKU & $2(0.5 \%)$ \\
RV & $94(25.5 \%)$ \\
Enterovirus & $6(1.6 \%)$ \\
hMPV & $23(6.2 \%)$ \\
Boca Virus & $15(4.1 \%)$ \\
Parechovirus & $11(3.0 \%)$ \\
Adenovirus & $23(6.2 \%)$ \\
Other viruses & $20(5.4 \%)$ \\
\hline
\end{tabular}

$R S V$ Respiratory syncytial virus, $R V$ rhinovirus, $h M P V$ Human metapneumovirus. Quantitative data were presented in mean \pm SD. For some parameters the sum is not equal to total $n=369$ due to some missing observations and respective $\%$ were computed based on non-missing observations

frequency (percentage) and mean \pm SD or median and interquartile range (IQR) as appropriate. Descriptive statistics were used to summarise demographic, medical history, frequency of each virus and clinical characteristics of the patients. Associations between two or more qualitative variables were assessed using chi-square test and Fisher Exact test as appropriate. Quantitative data between the two independent groups were analysed using unpaired ' $t$ ' and Mann Whitney U tests as appropriate.

Univariate and multivariate logistic regression methods were used to assess and compute the predictive values of each predictor or risk factors for severity of bronchiolitis and hospital length of stay. For multivariate regression models, variables were considered if statistically significant at the $P<0.10$ level in univariate analysis or if determined to be clinically important. The results of logistic regression analyses were reported as odds ratio (OR) with 95\% confidence intervals (CIs). Pictorial presentations of the key results were made using appropriate statistical graphs. A two-sided $P$ value $<0.05$ was considered to be statistically significant. All statistical analyses were done using statistical packages SPSS 22.0 (SPSS Inc. Chicago, IL) and Epi Info 2000 (Centres for Disease Control and Prevention, Atlanta, GA).

\section{Results}

\section{Patient identification and demographics}

A total of 369 children were admitted to the hospital with a clinical diagnosis of bronchiolitis documented in their medical charts during the study period with 261 (75.2\%) aged 3 months or younger and 247 (67\%) were male sex as illustrated in Table 1 . Of the 369 cases, 145 (39.3\%) had a family history of atopy or asthma. On 


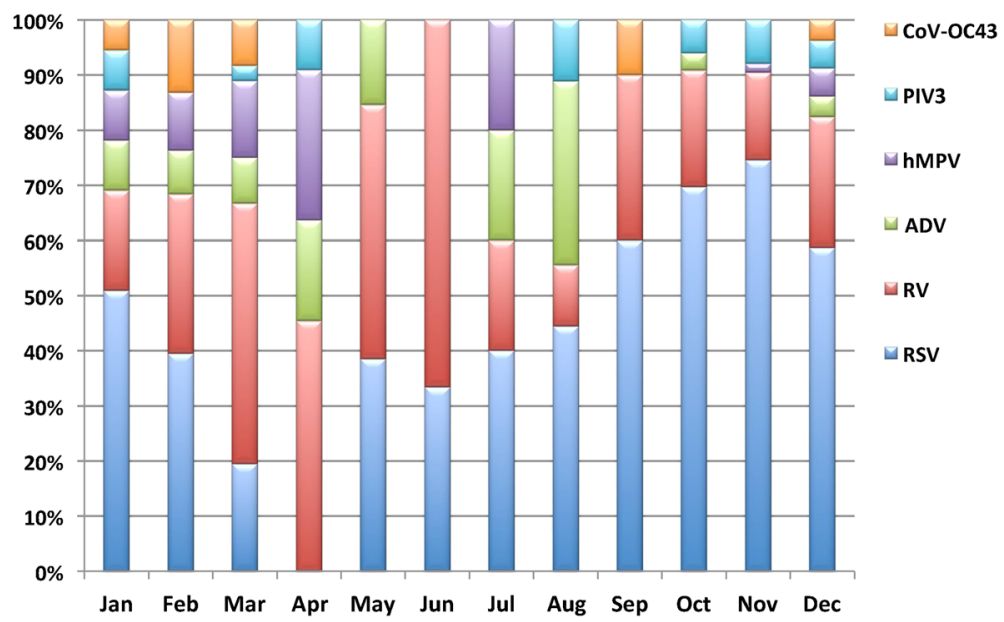

Fig. 1 Monthly trends of respiratory viruses
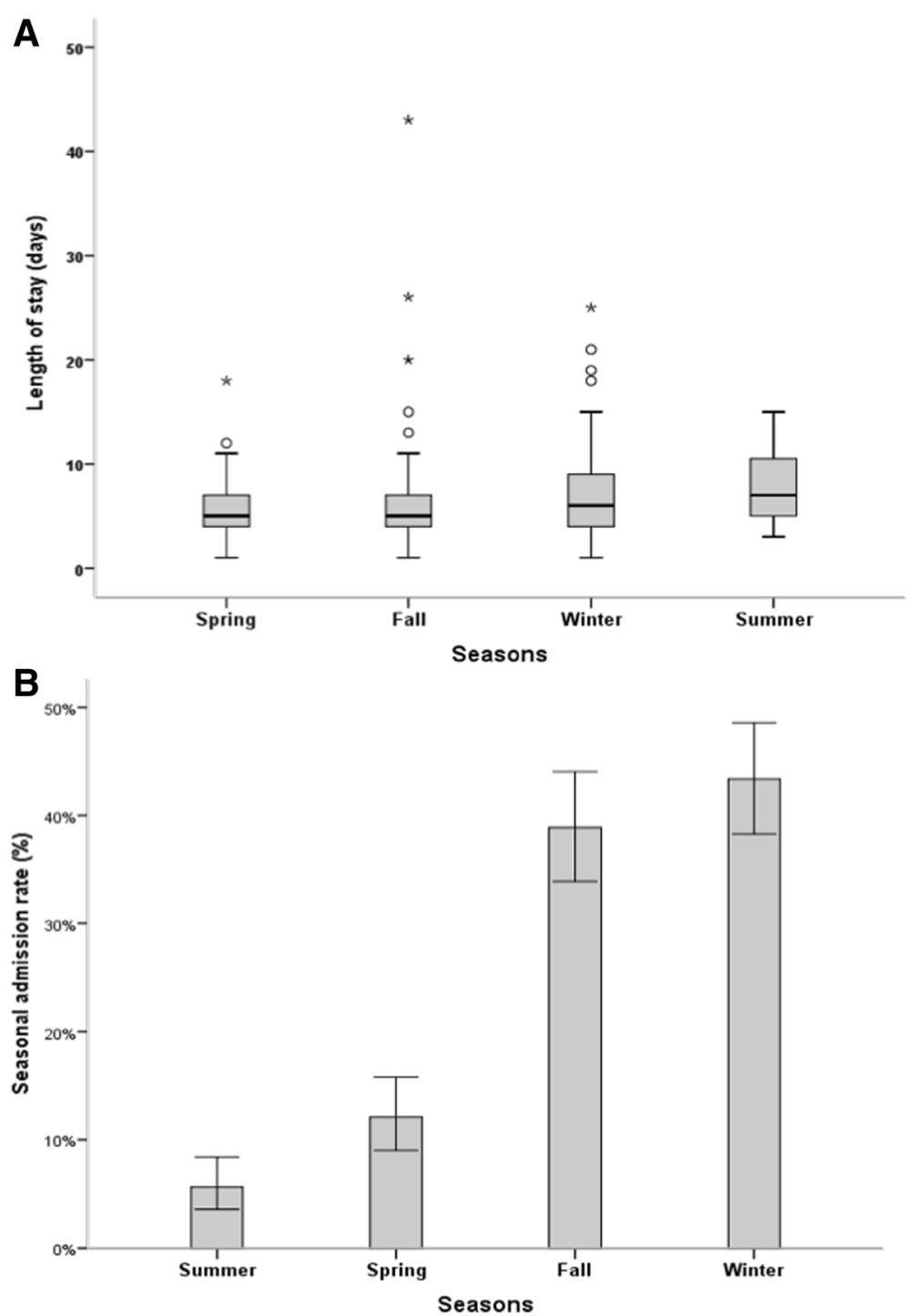

Fig. 2 a Length of stay, in days, across different seasons. b Seasonal variations in hospital admission rates (\%) 
Table 2 Management and complications of acute bronchiolitis

\begin{tabular}{ll}
\hline Characteristics & Frequency (\%) \\
\hline Assisted ventilation & $32(8.7 \%)$ \\
Yes & \\
Assisted ventilation type $(n=32)$ & $22(6 \%)$ \\
Non-invasive & $1(0.3 \%)$ \\
Invasive & $9(2.4 \%)$ \\
Both & \\
Therapy/Treatment $(n=369)$ & $331(89.7 \%)$ \\
$\beta$ agonist & $151(40.9 \%)$ \\
Adrenaline & $42(11.4 \%)$ \\
0.9\% saline & $160(43.4 \%)$ \\
3.0\% saline & $85(23 \%)$ \\
Steroids & $239(64.8 \%)$ \\
Antibiotics & $6(1.6 \%)$ \\
Mucomist & $38(10.3 \%)$ \\
Atrovent & \\
Complications $(n=369)$ & $76(20.6 \%)$ \\
Collapse & $0(0)$ \\
Barotrauma & $97(26.3 \%)$ \\
Atelectasis & $63(17.1 \%)$ \\
Pneumonia & $20(5.4 \%)$ \\
Acute respiratory distress syndrome & $0(0)$ \\
\hline
\end{tabular}

admission, 348 (94.3\%) and 270 (73.2\%) presented with cough and crepitation respectively, 261 (70.7\%) had fever, while 251 (68.0\%) and 231 (62.6\%) experienced retracted breathing and wheezing respectively. Vitals signs (mean \pm SD) including temperature 38.49 $\pm 0.80{ }^{\circ} \mathrm{C}$, respiratory rate $62.51 \pm 13.65$ breaths per minute, pulse rate $167.88 \pm 19.18 \mathrm{bpm}$ and $\mathrm{O}_{2}$ saturation $96.40 \pm 2.46 \%$ were recorded in the majority of the children. Generally, there were no differences in the clinical presentations between the males and the females. However, pertussis like symptoms were more frequently reported in females, $14 / 122$ (11.5\%), compared to males, $15 / 247$ (6.1\%).

\section{Seasonal distribution}

The seasonal pattern of RSV and RV were generally distributed all year around although incidence of RSV infection peaked during the fall season whereas RV peaked during the spring. The findings of the current study revealed more adenovirus (ADV) infections in the summer months than spring (Fig. 1). Coronavirus (CoV-OC43) circulated predominantly during the winter months while parainfluenza virus 3 (PIV3) during the fall but sporadically across the year. Dual peaks were observed for human metapneumovirus (hMPV) during the spring and winter seasons.
The median LOS was longer during the summer (7 days) compared to the winter ( 6 days) and shortest in the fall and spring (5 days), Fig. 2a. Our findings show a peak in hospital admission rates during the winter season, 154 (41.7\%), followed by the fall, 138 (37.4\%) with least during the summer season, 20 (5.4\%) as presented in Fig. 2b.

\section{Viral aetiologies and multiple co-infections}

We used polymerase chain reaction (PCR) to establish the viral aetiology of acute bronchiolitis. At least one virus was detected in $315 / 369(85.4 \%)$ of children with single virus in $211 / 315(67 \%)$ and multiple viruses in 104/315 (33.0\%). RSV was the most common virus identified, accounting for 189 cases (51.2\%) followed by RV in 94 cases (25.5\%), 23 cases (6.2\%) of hMPV and ADV each. Influenza $A$ and $B$ were the least detected viruses accounting for less than $1 \%$ of the cases, as shown in Table 1.

Out of the 315 samples analysed, 27.3\% had dual infections and three viruses were detected in $5.4 \%$ of the sample with a quadruple infection found in one case. There were no marked differences in the management of single and multiple infections. $\beta$-agonists were used in the majority of cases, followed by antibiotics, hypertonic saline and adrenaline, presented in Table 2.

\section{Respiratory viruses distribution by age-group, gender, medical history and clinical presentation}

Children were grouped into three age groups with different rates of single and multiple viral infections, Table 3. In children aged $<1$ month, the most common detected virus was RSV (47.9\%); for those between 1 and 3 months of age, RV (47.2\%) was the most common virus. Children aged $>3$ months were found to be co-infected with RSV + RV (40\%). Co-infection with RSV+ non-RV (75.8\%) had the highest incidence in males whereas in females, RV+ non-RSV co-infection (40.9\%) dominated. Family history of atopy or asthma, $P=0.008$, and high respiratory rate, $P=0.026$, were more common in $\mathrm{RV}$ single group, whereas crepitation was more frequent in the RSV+ non-RV co-infection group, $P=0.039$. More children in the RV single group (91.7\%) had LOS $\geq 4$ days compared to the RSV single group (82.4\%). Similar pattern was observed in terms of bronchiolitis severity with more children in the RV single group $(65.7 \%)$ with moderate to severe bronchiolitis compared to children in the RSV single group (57.6\%).

\section{Analysis of risk factors of length of hospital stay and bronchiolitis severity}

A total of 291 (82.4) had a LOS $\geq 4$ days. On univariate logistic regression analysis, admission during the fall season (unadjusted OR 1.89; 95\% CI 1.01,3.53; $P=0.046$ ), cough (unadjusted OR $7.27 ; 95 \%$ CI $1.2,44.5 ; P=0.032$ ), retraction (unadjusted OR 2.70; 95\% CI 1.5,5.1; $P=0.002$ ), pulse 
Table 3 Demographic characteristics, clinical presentations and seasonality of acute bronchiolitis by RSV, RV and other co-infections

\begin{tabular}{|c|c|c|c|c|c|c|c|c|}
\hline & & $\operatorname{RSV}(n=127)$ & $\operatorname{RV}(n=36)$ & $\begin{array}{l}\text { RSV + RV } \\
(n=25)\end{array}$ & $\begin{array}{l}\text { RSV+ any other } \\
\text { non- } \operatorname{RV}(n=33)\end{array}$ & $\begin{array}{l}\text { RV+ any other } \\
\text { non-RSV }(n=22)\end{array}$ & $\begin{array}{l}\text { Others } \\
(n=72)\end{array}$ & $P$-value* \\
\hline \multirow[t]{2}{*}{ Gender } & Male & 76 (59.8) & $27(75)$ & $15(60)$ & $25(75.8)$ & $13(59.1)$ & $53(73.6)$ & 0.180 \\
\hline & Female & $51(40.2)$ & $9(25)$ & $10(40)$ & $8(24.2)$ & $9(40.9)$ & 19 (26.4) & \\
\hline \multirow[t]{3}{*}{ Age Group } & $<1$ months & $57(47.9)$ & $14(38.9)$ & $4(16)$ & $8(25)$ & $8(36.4)$ & $28(42.4)$ & 0.064 \\
\hline & 1 to 3 months & $33(27.7)$ & $17(47.2)$ & $11(44)$ & $12(37.5)$ & $8(36.4)$ & $23(34.8)$ & \\
\hline & $>3$ months & $29(24.4)$ & $5(13.9)$ & $10(40)$ & $12(37.5)$ & $6(27.3)$ & $15(22.7)$ & \\
\hline Nationality & Qatari & 90 (70.9) & $22(61.1)$ & $16(64)$ & $22(66.7)$ & $11(50)$ & $42(58.3)$ & 0.335 \\
\hline \multirow{12}{*}{$\begin{array}{l}\text { Clinical and presenting } \\
\text { symptoms }\end{array}$} & Cough & $124(100)$ & 35 (97.2) & $25(100)$ & $32(97)$ & $22(100)$ & $66(97.1)$ & 0.408 \\
\hline & Wheezing & $83(68)$ & $26(72.2)$ & 20 (83.3) & $22(68.8)$ & $13(59.1)$ & $42(62.7)$ & 0.471 \\
\hline & Crepitation & 88 (78.6) & $30(85.7)$ & $22(91.7)$ & $25(96.2)$ & $16(76.2)$ & $56(93.3)$ & 0.039 \\
\hline & Retraction & $89(76.7)$ & $29(82.9)$ & $18(75)$ & $28(90.3)$ & $13(59.1)$ & $50(82)$ & 0.121 \\
\hline & Fever & $90(74.4)$ & $25(71.4)$ & $19(79.2)$ & $28(87.5)$ & $16(80)$ & $51(79.7)$ & 0.621 \\
\hline & Apnea & $8(7.3)$ & $1(3.1)$ & $3(13)$ & $1(4.2)$ & $1(5.3)$ & $8(13.8)$ & 0.415 \\
\hline & Pertussis like symptoms & $9(8.3)$ & $3(11.5)$ & $5(20)$ & $2(8.3)$ & $3(15.8)$ & $5(10.2)$ & 0.613 \\
\hline & $\begin{array}{l}\text { Family history of atopy } \\
\text { or asthma }\end{array}$ & $54(61.4)$ & $20(69)$ & $10(45.5)$ & $14(56)$ & $3(16.7)$ & $29(59.2)$ & 0.008 \\
\hline & $\begin{array}{l}\text { Max. temperature } \\
\text { (degree C) }\end{array}$ & $38.49 \pm 0.82$ & $38.52 \pm 0.88$ & $38.64 \pm 0.77$ & $38.49 \pm 0.79$ & $38.63 \pm 0.74$ & $38.36 \pm 0.84$ & 0.687 \\
\hline & $\begin{array}{l}\text { Max. respiratory rate } \\
\text { (Br/min) }\end{array}$ & $61.3 \pm 9.5$ & $67.5 \pm 20.1$ & $60.3 \pm 9.4$ & $62.3 \pm 7.1$ & $59.6 \pm 8.0$ & $66.8 \pm 20.5$ & 0.026 \\
\hline & Max. Pulse (Beat/min) & $167.5 \pm 15.2$ & $170 \pm 34$ & $172.2 \pm 14.8$ & $164.2 \pm 16.2$ & $169 \pm 10.8$ & $168.4 \pm 23.1$ & 0.750 \\
\hline & O2 Saturation & $96.57 \pm 2.40$ & $95.25 \pm 2.73$ & $96.55 \pm 1.60$ & $95.8 \pm 3.48$ & $96.29 \pm 1.87$ & $96.42 \pm 2.24$ & 0.087 \\
\hline ICS score & 3 to 4 & $72(57.6)$ & $23(65.7)$ & $14(58.3)$ & $17(56.7)$ & $10(45.5)$ & $34(51.5)$ & 0.692 \\
\hline \multirow[t]{4}{*}{ Seasons } & Winter & $44(34.9)$ & $17(47.2)$ & $14(56)$ & $13(39.4)$ & $11(50)$ & $27(40.9)$ & 0.483 \\
\hline & Spring & $14(11.1)$ & $6(16.7)$ & $4(16)$ & $3(9.1)$ & $0(0)$ & $9(13.6)$ & \\
\hline & Summer & $12(9.5)$ & $1(2.8)$ & $1(4)$ & $2(6.1)$ & $2(9.1)$ & $2(3)$ & \\
\hline & Fall & $56(44.4)$ & $12(33.3)$ & $6(24)$ & $15(45.5)$ & $9(40.9)$ & $28(42.4)$ & \\
\hline Assisted ventilation & Yes & $12(10)$ & $6(16.7)$ & $1(4.3)$ & $2(6.1)$ & $2(9.5)$ & $8(12.3)$ & 0.642 \\
\hline LOS (days) & $\geq 4$ days & $103(82.4)$ & $33(91.7)$ & $21(87.5)$ & $30(90.9)$ & $19(86.4)$ & $56(84.8)$ & 0.703 \\
\hline
\end{tabular}

LOS Length of stay in hospital, ICS Initial clinical severity score. ${ }^{*}$-values computed using one-way analysis of variance (ANOVA). Chi-square and Yates corrected Chi-square statistical tests methods

rate (unadjusted OR 1.01; 95\% CI 1.0,1.03; $P=0.011$ ) were significantly associated with longer LOS as shown in Table 4. Oxygen saturation level (unadjusted OR 0.78; 95\% CI $0.66,0.89 ; P=0.001$ ) was associated with shorter LOS. Detection of RV, RSV+ non-RV, age group 1-3 months and admission during the summer season increased LOS but these differences did not reach statistical significance $(P>0.05)$. On multivariate logistic regression analysis, the only factors that remained statistically significant were retraction (adjusted OR 3.96; 95\% CI $1.64,9.59 ; P=0.002$ ), age group $1-3$ months (adjusted OR 3.09; 95\% CI 1.06,9.05; $P=0.039$ ) and high respiratory rate (adjusted OR 1.07; 95\% CI 1.0,1.14; $P=0.05$ ), provided in Additional file 1: Table S2.

A total of 185 (53.4\%) of the hospitalised children experienced moderate to severe bronchiolitis. On univariate logistic regression analysis, children in this group required greater need for respiratory support (OR 5.85; 95\% CI 1.98,17.3; $P=0.001)$, experienced more wheezing (OR 1.82; 95\% CI 1.15,2.89; $P=0.010$ ), crepitation (OR 3.11; 95\% CI 1.64,5.90; $P=0.001$ ), and retraction (OR 5.65; 95\% CI 3.13,10.2; $P<0.001$ ), increased respiratory rate (OR 1.09; 95\% CI 1.07,1.12; $P<0.001)$, increased pulse rate (OR 1.03; 95\% CI 1.02,1.04; $P<0.001)$, but higher oxygen saturation levels reduced the odds of moderate to severe bronchiolitis (OR $0.85 ; 95 \%$ CI $0.77,0.93 ; P=0.001$ ) as presented in Table 5 . On multivariate logistic regression analysis, crepitation (adjusted OR 9.15; 95\% CI 1.58,53.13; $P=0.014$ ), retraction (OR 4.10; 95\% CI 1.05,16.12; $P=0.043$ ), and increased respiratory rate (adjusted OR 1.46; 95\% CI 1.28,1.66; $P<0.001$ ) were significant predictors associated with bronchiolitis severity, provided in Additional file 1: Table S3. Complications including atelectasis, collapse, pneumonia and sepsis were 
Table 4 Predictors of length-of-stay $\geq 4$ days among children with mild to severe bronchiolitis: logistic regression analysis

\begin{tabular}{|c|c|c|c|c|}
\hline & LOS $<4$ days & LOS $\geq 4$ days & Odds Ratio (OR) (95\% Cl) & $P$-Value \\
\hline \multicolumn{5}{|l|}{ Demographic characteristics } \\
\hline \multicolumn{5}{|l|}{ Age group } \\
\hline$\leq 1$ month & $25(42.4 \%)$ & $118(41.5 \%)$ & $1.36(0.70,2.7)$ & 0.369 \\
\hline 1 to 3 months & $15(25.4 \%)$ & $100(35.2 \%)$ & $1.92(0.91,4.0)$ & 0.086 \\
\hline$>3$ months & $19(32.2 \%)$ & $66(23.2 \%)$ & 1.0 (Reference) & \\
\hline Male & $39(62.9 \%)$ & $196(67.4 \%)$ & $1.22(0.69,2.15)$ & 0.500 \\
\hline Female & $23(37.1 \%)$ & $95(32.6 \%)$ & 1.0 (Reference) & \\
\hline Qatari & $38(61.3 \%)$ & $185(63.6 \%)$ & $1.1(0.63,1.9)$ & 0.735 \\
\hline Non-Qatari & $24(38.7 \%)$ & $106(36.4 \%)$ & 1.0 (Reference) & \\
\hline \multicolumn{5}{|c|}{ Types of viruses, seasonal trend and severity } \\
\hline RSV & $22(50 \%)$ & $103(39.3 \%)$ & 1.0 (Reference) & \\
\hline RV & $3(6.8 \%)$ & $33(12.6 \%)$ & $2.35(0.66,8.35)$ & 0.187 \\
\hline RSV + RV & $3(6.8 \%)$ & $21(8 \%)$ & $1.50(0.41,5.46)$ & 0.542 \\
\hline RSV+ any other non-RV & $3(6.8 \%)$ & $30(11.5 \%)$ & $2.14(0.60,7.63)$ & 0.243 \\
\hline RV+ any other non-RSV & $3(6.8 \%)$ & $19(7.3 \%)$ & $1.35(0.37,4.97)$ & 0.649 \\
\hline Others & $10(22.7 \%)$ & $56(21.4 \%)$ & $1.20(0.53,2.70)$ & 0.667 \\
\hline \multicolumn{5}{|l|}{ Seasons } \\
\hline Spring & $8(12.9 \%)$ & $35(12 \%)$ & $1.25(0.53,2.90)$ & 0.610 \\
\hline Summer & $2(3.2 \%)$ & $18(6.2 \%)$ & $2.57(0.57,11.6)$ & 0.220 \\
\hline Fall & $18(29 \%)$ & $119(41 \%)$ & $1.89(1.01,3.53)$ & 0.046 \\
\hline Winter & $34(54.8)$ & $119(40.9)$ & 1.0 (Reference) & \\
\hline ICS score: 3 to 4 & $27(43.5 \%)$ & $156(55.5 \%)$ & $1.62(0.93,2.82)$ & 0.089 \\
\hline ICS score: 1 to 2 & $35(56.5 \%)$ & $125(44.5 \%)$ & 1.0 (Reference) & \\
\hline \multicolumn{5}{|c|}{ Medical history and physical exam findings } \\
\hline Cough & $59(95.2 \%)$ & $286(99.3 \%)$ & $7.27(1.2,44.5)$ & 0.032 \\
\hline Wheezing & $40(66.7 \%)$ & $189(66.5 \%)$ & $0.99(0.55,1.8)$ & 0.986 \\
\hline Crepitation & $42(76.4 \%)$ & $226(85.6 \%)$ & $1.84(0.90,3.7)$ & 0.092 \\
\hline Retraction & $33(60 \%)$ & $215(80.2 \%)$ & $2.70(1.5,5.1)$ & 0.002 \\
\hline Fever & $47(78.3 \%)$ & $212(76.3 \%)$ & $0.89(0.45,1.74)$ & 0.731 \\
\hline Apnea & $3(5.6 \%)$ & $21(8.4 \%)$ & $1.56(0.45,5.4)$ & 0.485 \\
\hline Pertussis like symptoms & $3(5.5 \%)$ & $26(11 \%)$ & $2.15(0.63,7.4)$ & 0.225 \\
\hline Family history of asthma & $22(55 \%)$ & $121(56.3 \%)$ & $1.1(0.53,2.1)$ & 0.881 \\
\hline Maximum temperature $\left({ }^{\circ} \mathrm{C}\right)$ & $38.39 \pm 0.87$ & $38.52 \pm 0.78$ & $1.22(0.86,1.73)$ & 0.255 \\
\hline Maximum respiratory rate $(\mathrm{br} / \mathrm{m})$ & $60.34 \pm 15.13$ & $62.99 \pm 13.32$ & $1.02(0.99,1.1)$ & 0.160 \\
\hline Maximum pulse rate (beat/m) & $161.8 \pm 22.1$ & $169.1 \pm 18.1$ & $1.01(1.0,1.03)$ & 0.011 \\
\hline $\mathrm{O}_{2}$ saturation (\%) & $97.37 \pm 1.84$ & $96.18 \pm 2.53$ & $0.78(0.66,0.89)$ & 0.001 \\
\hline
\end{tabular}

LOS Length of stay in hospital, ICS Initial clinical severity score, OR odds ratio, $\mathrm{Cl}$ confidence interval. Dichotomous outcome LOS $<4$ days considered as reference group

reported in 97 (26.3\%), 76(20.6\%), 63(17.1\%) and 20(5.4\%) of hospitalised children respectively.

\section{Discussion}

To our knowledge this is the first comprehensive report on viral aetiology in hospitalised children with bronchiolitis in the State of Qatar. Our study revealed that RSV and RV were the most commonly detected causative agents. This finding is in contrast to a previous report with a small sample size of 56 children with respiratory tract infection (RTI) in Qatar in which hMPV was the most frequently isolated virus [10]. Our findings are, however, in line with a number of large studies conducted in the Middle East and elsewhere [11-14]. In Jordanian 
Table 5 Predictors of mild to severe ICS score among children with viral bronchiolitis: logistic regression analysis

\begin{tabular}{|c|c|c|c|c|}
\hline & ICS score: 1 to 2 (mild) & ICS score: 3 to 4 (moderate to severe) & Odds Ratio (OR) $(95 \% \mathrm{Cl})$ & P-Value \\
\hline \multicolumn{5}{|l|}{ Demographic characteristics } \\
\hline \multicolumn{5}{|l|}{ Age group } \\
\hline$\leq 1$ month & $70(44.0 \%)$ & $68(38.4 \%)$ & $0.84(0.49,1.45)$ & 0.535 \\
\hline 1 to 3 months & $50(31.4 \%)$ & $64(36.2 \%)$ & $1.11(0.63,1.95)$ & 0.720 \\
\hline$>3$ months & $39(24.5 \%)$ & $45(25.4 \%)$ & 1.0 (Reference) & \\
\hline Male & $101(62.7 \%)$ & $131(70.8 \%)$ & $1.44(0.92,2.26)$ & 0.111 \\
\hline Female & $60(37.3 \%)$ & $54(29.2 \%)$ & 1.0 (Reference) & \\
\hline Qatari & $97(60.2 \%)$ & $123(66.5 \%)$ & $1.31(0.84,2.03)$ & 0.229 \\
\hline Non-Qatari & $64(39.8 \%)$ & $62(33.5 \%)$ & 1.0 (Reference) & \\
\hline \multicolumn{5}{|c|}{ Types of viruses, seasonal trend and severity } \\
\hline RSV & $53(40.2 \%)$ & $72(42.4 \%)$ & 1.0 (Reference) & \\
\hline RV & $12(9.1 \%)$ & $23(13.5 \%)$ & $1.41(0.65,3.09)$ & 0.389 \\
\hline$R S V+R V$ & $10(7.6 \%)$ & $14(8.2 \%)$ & $1.03(0.42,2.50)$ & 0.947 \\
\hline RSV+ any other non-RV & $13(9.8 \%)$ & $17(10 \%)$ & $0.96(0.43,2.15)$ & 0.926 \\
\hline RV+ any other non-RSV & $12(9.1 \%)$ & $10(5.9 \%)$ & $0.61(0.25,1.53)$ & 0.293 \\
\hline Others & $32(24.2 \%)$ & $34(20 \%)$ & $0.78(0.43,1.42)$ & 0.421 \\
\hline \multicolumn{5}{|l|}{ Seasons } \\
\hline Winter & $62(38.5 \%)$ & $88(47.8 \%)$ & 1.0 (Reference) & \\
\hline Spring & $23(14.3 \%)$ & $19(10.3 \%)$ & $0.58(0.29,1.16)$ & 0.124 \\
\hline Summer & $6(3.7 \%)$ & $13(7.1 \%)$ & $1.53(0.55,4.24)$ & 0.417 \\
\hline Fall & $70(43.5 \%)$ & $64(34.8 \%)$ & $0.64(0.40,1.03)$ & 0.066 \\
\hline $\operatorname{LOS} \geq 4$ days $^{\mathrm{a}}$ & $125(78.1 \%)$ & $156(85.2 \%)$ & $1.62(0.93,2.82)$ & 0.089 \\
\hline Assisted Ventilation ${ }^{a}$ & $4(2.6 \%)$ & $24(13.4 \%)$ & $5.85(1.98,17.3)$ & 0.001 \\
\hline \multicolumn{5}{|c|}{ Medical history and physical exam findings } \\
\hline Cough & $158(98.8 \%)$ & $181(98.4 \%)$ & $0.76(0.13,4.63)$ & 0.769 \\
\hline Wheezing & $95(60.1 \%)$ & $132(73.3 \%)$ & $1.82(1.15,2.89)$ & 0.010 \\
\hline Crepitation & $109(75.7 \%)$ & $155(90.6 \%)$ & $3.11(1.64,5.90)$ & 0.001 \\
\hline Retraction & $87(60.8 \%)$ & $158(89.8 \%)$ & $5.65(3.13,10.2)$ & $<0.001$ \\
\hline Fever & $118(75.6 \%)$ & $135(76.3 \%)$ & $1.03(0.63,1.71)$ & 0.893 \\
\hline Apnea & $13(9.3 \%)$ & $9(5.6 \%)$ & $0.58(0.24,1.40)$ & 0.224 \\
\hline Pertussis like symptoms & $12(9.2 \%)$ & $16(10.1 \%)$ & $1.12(0.51,2.46)$ & 0.782 \\
\hline Family history of asthma & $59(52.7 \%)$ & $81(58.3 \%)$ & $1.26(0.76,2.07)$ & 0.375 \\
\hline Maximum temperature $\left({ }^{\circ} \mathrm{C}\right)$ & $38.44 \pm 0.82$ & $38.56 \pm 0.79$ & $1.20(0.92,1.56)$ & 0.156 \\
\hline Maximum respiratory rate $(\mathrm{br} / \mathrm{m})$ & $57.98 \pm 17.17$ & $66.37 \pm 7.83$ & $1.09(1.07,1.12)$ & $<0.001$ \\
\hline Maximum pulse rate (beat/m) & $163.2 \pm 19.9$ & $171.9 \pm 17.7$ & $1.03(1.02,1.04)$ & $<0.001$ \\
\hline $\mathrm{O}_{2}$ saturation (\%) & $96.91 \pm 2.01$ & $96.02 \pm 2.64$ & $0.85(0.77,0.93)$ & 0.001 \\
\hline
\end{tabular}

LOS Length of stay in hospital, OR odds ratio, Cl confidence interval, ICS Initial clinical severity score. ${ }^{a}$ Reference category: LOS $<4$ days; not assisted ventilation. Dichotomous outcome ICS score value 1 to 2 was taken as reference group

children of less than 2 years of age, RSV was a major cause of hospitalisation [11]. Other studies conducted in Saudi Arabia and Turkey reported the same $[15,16]$.

Geographic variations in seasonal activity of the most commonly detected respiratory viruses have been reported in the literature. In temperate countries, RSV peaks during the winter season, but with variation in the tropics. This diversity is mainly attributed to the region's climate characteristics, i.e. relative humidity, average monthly temperature and rainfall [17-19]. In their study, Haynes et al. assessed RSV seasonality in seven countries with diverse climate characteristics and found that RSV onset and peak timings were inconsistent with climate characteristics in all assessed countries 
apart from Thailand. RSV offset was found to be consistent in Guatemala [20]. Rhinovirus A was detected all year around with high proportion by the onset of summer in Japan but during the fall and spring in Cyprus while Rhinovirus $\mathrm{C}$ was mainly detected in the winter but during the fall and spring in Japan and Cyprus, respectively $[18,21]$.

In this study, RSV exhibited a strong seasonal pattern with peak activity during the fall and summer months, in contrast to RV, which showed minimal circulation during the fall.

In comparison to children with RSV only infections, children infected with RSV in combination with non-RV or RV alone were more likely to have longer LOS. However, we found no significant association between single or multiple infections and disease severity or LOS. The findings are consistent with two large studies conducted in North America and Europe [13, 14], but in contrast with previous reports where RV was associated with shorter LOS [12, 22]. These discrepancies might be related to sample size, study design and variation in host risk factors.

In this study, we noted an association between individual components of the clinical severity score and bronchiolitis outcome after adjusting for clinical and demographic factors. Similar to Ricart et al., McCallum et al. and Weisgerber et al., the data indicate that, in the Qatari community, children's clinical characteristics are more relevant than the specific infecting viruses in determining the duration of LOS and disease severity [23-25].

Detection of the presence of multiple infections has become common in practice although its clinical impact on disease management and predicting outcomes remains unclear [26]. By using RT-PCR to quantify viral load, a number of studies have concluded that RSV genomic load is correlated with disease severity [13, 14]. Similarly, two investigational anti-RSV drugs showed promising results in reducing viral load and clinical disease severity [27, 28].

Some studies have determined severity based on a modified Wood-Downes score or the need for paediatric intensive care unit (PICU) admission [7, 23]. In this study we analysed severity based on a clinical score that allows children's classification according to respiratory rate, oxygen saturation and physical examination, mirroring the severity of the respiratory burden.

Previous studies have reported males to be more susceptible than females to lower RTIs across different age groups [29]. In this study the percent of males with severe bronchiolitis was as twice as that to females, 70.8 vs. $29.2 \%$. An explanation was suggested two decades ago by Gupta et al. in which the disproportionally narrower peripheral airways in the younger males could be a possible mechanism of the observed difference [30].
Childhood respiratory infection may influence the development of chronic respiratory diseases. In a cohort of 47 Swedish hospitalised infants with RSVbronchiolitis, asthma was prevalent in 30\% of the group when aged 7 years increasing to $37 \%$ at the age of 13 [31]. While Jackson et al. noted an increase in asthma risk in children with RSV associated wheezing; RV was associated with a 10-fold increase of asthma [32]. An earlier retrospective study from Qatar noted an increase in recurrent wheezing by $44 \%$ in hospitalised infants due to RSV bronchiolitis 2 years after admission compared to $12 \%$ in the control group [33]. In the current study, $63 \%$ of the admitted children had wheezing of which 51.2\% had RSV associated bronchiolitis. Compared to RSV, RV associated bronchiolitis is suggested to occur in older infants, 13 versus 5 months, who present more often with atopic dermatitis and blood eosinophilia [34].

This study has potential limitations. First, it is a retrospective study at a single hospital. Another limitation is that data on concomitant bacterial infection, viral genomic load and palivizumab prophylaxis were not collected.

\section{Conclusions}

In summary, RSV was the most common virus identified, followed by RV with peaks during the fall and spring seasons respectively. Our data show that the clinical presentation is more related to the duration of hospital stay and disease severity than the detected viruses.

Conducting a prospective, multi site surveillance of viral bronchiolitis in the warm, desert climate of the Gulf Cooperation Council (GCC) countries will allow for proper timing of preventable measures. Future studies within the GCC countries should investigate the interplay between climate characteristics, population's factors and the most detectable circulating viruses.

\section{Additional file}

Additional file 1: Table S1. Bronchiolitis severity score; Table S2. Predictors of hospital length-of-stay $\geq 4$ days among children with mild to severe bronchiolitis associated with different viruses: multivariate logistic regression analysis; Table S3. Predictors of moderate (1 to 2 ) to severe (3 to 4 ) ICS score among children with viral aetiology of acute bronchiolitis: multivariate logistic regression analysis. (DOCX $33 \mathrm{~kb}$ )

Abbreviations

ADV: Adenovirus; Cl: Confidence interval; CoV-OC43: Coronavirus; DCF: Data collection form; GCC: Gulf cooperation council; HGH: Hamad general hospital; hMPV: Human metapneumovirus; ICD: International classification of disease; IQR: Interquartile range; IRB: Institutional review board; LOS: Length of stay; OR: Odds ratio; PCR: Polymerase chain reaction; PICU: Paediatric intensive care unit; PIV3: Parainfluenza virus 3; RSV: Respiratory syncytial virus; RTI: Respiratory tract infection; RV: Rhinovirus 


\section{Acknowledgements}

The authors would like to thank Prem Chandra for his contribution to data analysis. The study was financially supported by Medical Research Centre, Hamad Medical Corporation, Qatar.

\section{Funding}

Hamad Medical Corporation-Medical Research Centre, Institutional Review Board (IRB) Number: 12054.

\section{Availability of data and materials}

The dataset generated and/or analysed during the current study available from the corresponding author on reasonable request.

\section{Authors' contributions}

IJ conceptualized and supervised study conduction, assisted in quality assurance and guided critical revisions in response to reviewers' feedback. $\mathrm{AAH}, \mathrm{FA}, \mathrm{MAH}$ and AA performed literature review and data collection. MA interpreted the data and wrote the manuscript. All authors read and approved the final manuscript.

\section{Competing interests}

The authors declare that they have no competing interests.

\section{Consent for publication}

Not applicable.

\section{Ethics approval and consent to participate}

The institutional review board (IRB) at Hamad Medical Corporation (HMC) approved the study. Waiver of the requirement of participants' informed consent was obtained from the IRB of HMC due to the retrospective nature of the study.

\section{Author details}

'Paediatric Pulmonology Unit, Hamad Medical Corporation, P. O. Box 3050, Doha, Qatar. ${ }^{2}$ Icahn School of Medicine at Mount Sinai, New York, USA.

Received: 16 October 2016 Accepted: 27 January 2017

Published online: 13 February 2017

\section{References}

1. DeNicola LK. Bronchiolitis: Practice essentials, background, pathophysiology. Medscape. 2016. http://emedicine.medscape.com/article/961963-overview. Accessed 1 Aug 2016.

2. Wainwright C. Acute viral bronchiolitis in children- a very common condition with few therapeutic options. Paediatr Respir Rev. 2010;11(1):39-45.

3. Green C, Yeates D, Goldacre A, Sande C, Parslow R, McShane P, Pollard A, Goldacre M. Admission to hospital for bronchiolitis in England: trends over five decades, geographical variation and association with perinatal characteristics and subsequent asthma. Arch Dis Child. 2015;101(2):140-6.

4. Ralston SL, Lieberthal AS, Meissner HC, et al. Clinical practice guideline: the diagnosis, management, and prevention of bronchiolitis. Pediatrics. 2014; 134(5):e1474-502.

5. Marguet C, Lubrano M, Gueudin M, Le Roux P, Deschildre A, Forget C, Couderc $L$, Siret $D$, Donnou $M$, Bubenheim $M$, et al. In very young infants severity of acute bronchiolitis depends on carried viruses. PLoS One. 2009; 4(2):e4596.

6. Asner SA, Science ME, Tran D, Smieja M, Merglen A, Mertz D. Clinical disease severity of respiratory viral co-infection versus single viral infection: A systematic review and meta-analysis. PloS ONE. 2014;9(6):e99392.

7. Richard N, Komurian-Pradel F, Javouhey E, Perret M, Rajoharison A, Bagnaud A, Billaud $G$, Vernet $G$, Lina B, Floret $D$, et al. The impact of dual viral infection in infants admitted to a pediatric intensive care unit associated with severe bronchiolitis. Pediatr Infect Dis J. 2008;27(3):213-7.

8. Richter J, Panayiotou C, Tryfonos C, Koptides D, Koliou M, Kalogirou N, Georgiou E, Christodoulou C. Aetiology of acute respiratory tract infections in hospitalized children in Cyprus. PLoS One. 2016;11(1):e0147041.

9. Cui B, Zhang D, Pan H, Zhang F, Farrar J, Law F, van Doorn H, Wu B, Ba-Thein W. Viral aetiology of acute respiratory infections among children and associated meteorological factors in southern China. BMC Infect Dis. 2015;15(1):124.
10. Al-Thani A, Azzam S, Al-Sheik Abboubaker H, Abdel-Hadi F, Elsheikh M, Janahi I. The role of human metapneumovirus in pediatric respiratory tract infection in Qatar. Future Virol. 2010;5(3):355-60.

11. Halasa N, Williams J, Faouri S, Shehabi A, Vermund S, Wang L, Fonnesbeck C, Khuri-Bulos N. Natural history and epidemiology of respiratory syncytial virus infection in the Middle East: hospital surveillance for children under age two in Jordan. Vaccine. 2015;33(47):6479-87.

12. Mansbach J, Piedra P, Teach S, Sullivan A, Forgey T, Clark S, et al. Prospective multicenter study of viral etiology and hospital length of stay in children with severe bronchiolitis. Arch Pediatr Adolesc Med. 2012;166(8):700-6.

13. Skjerven H, Megremis S, Papadopoulos N, Mowinckel P, Carlsen K, Lødrup CK Virus type and genomic load in acute bronchiolitis: severity and treatment response with inhaled adrenaline. J Infect Dis. 2015:213(6):915-21.

14. Hasegawa K, Jartti T, Mansbach J, Laham F, Jewell A, Espinola J, Piedra P, Camargo C. Respiratory syncytial virus genomic load and disease severity among children hospitalized with bronchiolitis: multicenter cohort studies in the United States and Finland. J Infect Dis. 2014;211(10):1550-9.

15. Al-Ayed MS, Asaad AM, Qureshi MA, Ameen MS. Viral etiology of respiratory infections in children in southwestern Saudi Arabia using multiplex reversetranscriptase polymerase chain reaction. Saudi Med J. 2014;35(11):1348-53.

16. Azkur D, Ozaydin E, Dibek-Misirlioglu E, Vezir E, Tombuloglu D, Kose G, Kocabas C. Viral etiology in infants hospitalized for acute bronchiolitis. Turk J Pediatr. 2014;56:592-6.

17. Bloom-Feshbach K, Alonso W, Charu V, Tamerius J, Simonsen L, Miller M, Viboud C. Latitudinal variations in seasonal activity of influenza and respiratory syncytial virus (RSV): a global comparative review. PLoS One. 2013;8(2):e54445.

18. Richter J, Nikolaou E, Panayiotou C, Tryfonos C, Koliou M, Christodoulou C. Molecular epidemiology of rhinoviruses in Cyprus over three consecutive seasons. Epidemiol Infect. 2014;143(9):1876-83.

19. Tsolia M, Kafetzis D, Danelatou K, Astra H, Kallergi K, Spyridis P, Karpathios T. Epidemiology of respiratory syncytial virus bronchiolitis in hospitalized infants in Greece. Eur J Epidemiol. 2002:18(1):55-61.

20. Haynes A, Manangan A, Iwane M, Sturm-Ramirez K, Homaira N, Brooks W, Luby S, Rahman M, Klena J, Zhang Y, et al. Respiratory syncytial virus circulation in seven countries with global disease detection regional centers. J Infect Dis. 2013:208 Suppl 3:246-54.

21. Morikawa S, Kohdera U, Hosaka T, Ishii K, Akagawa S, Hiroi S, Kase T. Seasonal variations of respiratory viruses and etiology of human rhinovirus infection in children. J Clin Virol. 2015;73:14-9.

22. Jartti T, Aakula M, Mansbach J, Piedra P, Bergroth E, Koponen P, Kivistö J, Sullivan A, Espinola J, Remes S, et al. Hospital length-of-stay is associated with rhinovirus etiology of bronchiolitis. Pediatr Infect Dis J. 2014;33(8):829-34.

23. Ricart S, Marcos M, Sarda M, Anton A, Muñoz-Almagro C, Pumarola T, Pons M, Garcia-Garcia J. Clinical risk factors are more relevant than respiratory viruses in predicting bronchiolitis severity. Pediatr Pulmonol. 2012;48(5):456-63.

24. Weisgerber M, Lye P, Li S, Bakalarski D, Gedeit R, Simpson P, Gorelick M. Factors predicting prolonged hospital stay for infants with bronchiolitis. J Hosp Med. 2011;6(5):264-70.

25. McCallum G, Chatfield M, Morris P, Chang A. Risk factors for adverse outcomes of indigenous infants hospitalized with bronchiolitis. Pediatr Pulmonol. 2015; 51(6):613-23.

26. Stollar F, Alcoba G, Gervaix A, Argiroffo C. Virologic testing in bronchiolitis: Does it change management decisions and predict outcomes? Eur J Pediatr. 2014;173(11):1429-35.

27. DeVincenzo J, McClure M, Symons J, Fathi H, Westland C, Chanda S, Lambkin-Williams R, Smith P, Zhang Q, Beigelman L, et al. Activity of oral ALS-008176 in a respiratory syncytial virus challenge study. NEJM. 2015; 373(21):2048-58.

28. DeVincenzo J, Whitley R, Mackman R, Scaglioni-Weinlich C, Harrison L, Farrell E, McBride S, Lambkin-Williams R, Jordan R, Xin Y, et al. Oral GS-5806 activity in a respiratory syncytial virus challenge study. NEJM. 2014;371(8):711-22.

29. Falagas M, Mourtzoukou E, Vardakas K. Sex differences in the incidence and severity of respiratory tract infections. Respir Med. 2007;101(9):1845-63.

30. Gupta R, Helms P, Jolliffe I, Douglas A. Seasonal variation in sudden infant death syndrome and bronchiolitis - a common mechanism? Am J Respir Crit Care Med. 1996;154(2):431-5.

31. Sigurs N, Gustafsson P, Bjarnason R, Lundberg F, Schmidt S, Sigurbergsson F Kjellman B. Severe respiratory syncytial virus bronchiolitis in infancy and asthma and allergy at age 13. Am J Respir Crit Care Med. 2005;171(2):137-41.

32. Jackson D, Gangnon R, Evans M, Roberg K, Anderson E, Pappas T, Printz M, Lee W, Shult P, Reisdorf E, et al. Wheezing rhinovirus illnesses in early life 
predict Asthma development in high-risk children. Am J Respir Crit Care Med. 2008;178(7):667-72.

33. Wahab A. Clinical characteristics of respiratory syncytial virus infection in hospitalized healthy infants and young children in Qatar. J Trop Pediatr. 2001;47(6):363-6.

34. Korppi M, Kotaniemi-Syrjanen A, Waris M, Vainionpaa R, Reijonen T. Rhinovirusassociated wheezing in infancy. Pediatr Infect Dis J. 2004;23(11):995-9.

Submit your next manuscript to BioMed Central and we will help you at every step:

- We accept pre-submission inquiries

- Our selector tool helps you to find the most relevant journal

- We provide round the clock customer support

- Convenient online submission

- Thorough peer review

- Inclusion in PubMed and all major indexing services

- Maximum visibility for your research

Submit your manuscript at www.biomedcentral.com/submit 